\title{
Indexical Tenses in Intensional Complements: implications from Albanian
}

\author{
Anastasia Smirnova \\ The Ohio State University
}

\section{Present tense in complements of propositional attitude verbs}

Recent literature on temporal semantics has shown that tenses embedded in complements of propositional attitude (PA) verbs such as believe, think, etc. are interpreted with respect to the time of the attitude, i.e. the attitude holder's now (e.g. Abusch 1997, Ogihara 1996, von Stechow 1995). Such analyses suggest that tenses in intensional complements are relative; they are interpreted differently from absolute or indexical tenses, i.e. tenses in matrix clauses, for which the evaluation time is the Speech Time (ST). To illustrate, in the Japanese example in (1), the state of Anna's being sick is non-past with respect to Ken's thinking time (not with respect to the ST):

$$
\begin{aligned}
& \text { Ken-wa [Anna-ga byooki da to] omot-ta. } \\
& \text { Ken-TOP Anna-NOM sick be.PRES COMP think-PAST } \\
& \text { 'Ken thought that Anna was sick (at the time of thinking),' }
\end{aligned}
$$

While this generalization holds for an impressive number of languages such as Dutch and Spanish (Kusumoto 1999), Hebrew (Sharvit 2003), Polish (Arregui \& Kusumoto 1998), Russian (e.g. Kondrashova 1998, Kubota et al. 2009), and Japanese (Ogihara 1996), the English present tense appears to violate this principle. In (2), the state of Anna's pregnancy denoted by the present tense verb overlaps with both the time of Ken's belief, thus having a property of a relative tense, but also with the ST, which is characteristic of an absolute tense. Following the previous literature (e.g. Abusch 1997), I will refer to such a reading as the Double Access (DA) interpretation.

Ken believed [that Anna is pregnant].

The DA phenomenon raises a question about the factors involved in the temporal

$\square$ I thank Judith Tonhauser and Yusuke Kubota for their extensive comments, and Brian Joseph for inspiring me to work on Albanian. Special thanks are also due to Bernard Comrie, Östen Dahl, Yael Sharvit, and Chris Worth, as well as to the anonymous SALT reviewers for valuable comments. Finally, I'm grateful to Arjola Hizmo and Xhuljeta Gjini for helping me with the Albanian data, and to Angelo Costanzo, Lauren Ressue and Chris Worth for their assistance with the editing process. The usual disclaimer applies. 
interpretation of tenses embedded in PA complements, namely whether the relevant information is encoded in the meaning of the present tense alone, or whether other factors, such as the semantics of PA verbs, constrain the temporal location of the embedded event.

There are two types of analysis proposed to account for the DA phenomenon in English. According to the approach advocated in Gennari (1999), (2003), the DA reading follows directly from the meaning of the present tense. The present tense in English specifies (i) that the eventuality denoted by the verb overlaps its local evaluation time (which is the time of the belief in (2)); and (ii) that the eventuality is non-past with respect to the ST. Thus, in Gennari's analysis, the present tense in English is both 'ST-sensitive' (or absolute) and 'evaluation time sensitive' (or relative).

The second type of analysis, represented most notably by Abusch (1997) and Ogihara (1996), is based on the assumption that the present tense in examples such as (2) is interpreted de re. According to such analyses, the meaning of the attitude verb and the present tense guarantee that (i) there exists a state in the actual world that overlaps both, the time of the belief and the ST; (ii) the attitude holder is acquainted with the interval in question via an acquaintance relation that causally relates him to the state in the actual world (in (2) it can be a situation in which Ken sees Anna in a loose dress, which makes her bigger than usual, and concludes that she is pregnant); (iii) the interval with which the attitude holder is acquainted is such that he ascribes to it the relevant property (in (2) it is a property of being an interval such that Anna is pregnant in it). This analysis is graphically represented in (3):

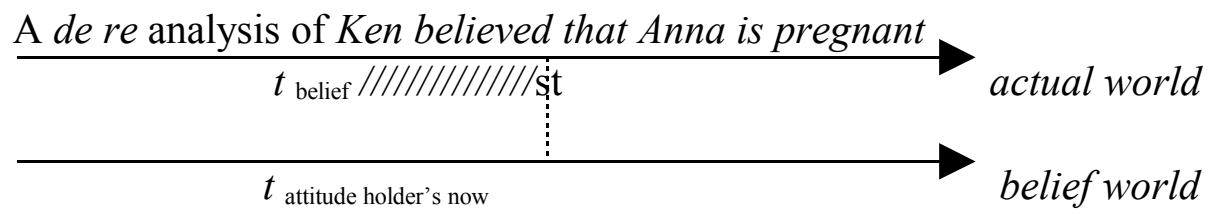

Thus, in analyses such as Abusch 1997, the DA reading is derived from the meaning of the present tense and from the mechanisms involved in the de re interpretation, such as the acquaintance relation.

Even though the two analyses differ in detail, both predict that an eventuality denoted by a present tense verb embedded under a past tense PA verb overlaps both with the time of the attitude and with the ST. While this is a correct prediction for English, the question arises whether the two analyses discussed above can explain the relevant data in other languages. Data from Albanian, a language that, similarly to English, shows the DA reading, might shed some light on this question. In the Albanian example in (4), the state of Maria's pregnancy has to overlap with both Peter's saying time and the ST. ${ }^{1}$

1The data presented here were collected from two native speakers of the Tosk Albanian dialect. I use the following glosses through the paper: COMP=Complementizer, FUT=Future marker, 
(4) Context: you watch a video of Peter's birthday party, which was recorded last week. You notice that Peter's wife Maria, who usually drinks a lot of wine, didn't drink at all. Your friend offers the following explanation:

Pjetri tha [se Maria është shtatzënë].

Peter say.3SG.PAST that Maria be.3SG.PRES pregnant.

'Peter said that Maria is pregnant.'

a. ... this is why he didn't offer her wine.

b. ... \#she gave birth to a boy.

The judgments in (a) and (b) show that the overlap with the time of the attitude and with the ST is obligatory. The utterance in (a) implies that Peter didn't offer wine to Maria because he knew that she was pregnant at the time of the party. This implication cannot be cancelled, i.e. the speaker cannot continue (4) by saying that Peter didn't know that Maria was pregnant at that time. This suggests that the state of Maria's pregnancy has to overlap with Peter's saying time. The utterance in (b) implies that Maria is no longer pregnant at the ST. The fact that it is infelicitous in the context of (4) suggests that the state of Maria's pregnancy has to overlap with the ST.

The parallels between the English and the Albanian examples in (2) and (4) suggest that the analyses developed for English can be applied to Albanian. However, Albanian differs from English in one important respect. In Albanian the present tense can also appear in PA complements selected by verbs such as planifikoj 'plan', vendos 'decide', etc. The corresponding verbs in English select either finite complements with the future tense or infinitival complements, but in Albanian these verbs select finite subjunctive complements. The example in (5) shows that the DA reading does not arise in such sentences.

$$
\begin{aligned}
& \text { Javen e shkuar Pjetri vendosi } \\
& \text { week LINK past Peter decide.3SG.PAST } \\
& \text { [Maria të flasë } \quad \text { me Benin \#dje /nesër]. } \\
& \text { Maria.NOM SUBJ talk.3SG.PRES with Beni yesterday/tomorrow } \\
& \text { 'Last week Peter decided that Maria will talk to Beni \#yesterday/tomorrow.' }
\end{aligned}
$$

First, the temporal adverbials in the matrix and in the embedded clause refer to different times, which excludes the overlap between the time of the attitude (Peter's decision time) and the event in the embedded clause (the time of Maria's conversation with Beni). Second, the embedded clause is compatible with the temporal adverbial nesër 'tomorrow', which shows that the embedded event does not overlap with the ST. Note also that the incompatibility of the present tense verb flase 'talk' with the past-oriented adverb dje 'yesterday' in (5) suggests that

IMPRFCT=Imperfect past tense, LINK=Linking particle, NOM=Nominative case, NOT $=$ Negation, $\mathrm{PAST}=$ Simple past tense (aorist), $\mathrm{PERF}=$ Perfective Aspect, $\mathrm{PRES}=$ Present tense, $\mathrm{SG}=$ Singular, $\mathrm{SUBJ}=$ Subjunctive marker, $\mathrm{TOP}=$ Topic. 
the embedded tense is ST-sensitive, as in (4). However, unlike (4), in (5) the event denoted by the present tense is located in the future with respect to the ST. The data in (5) cannot be explained by the analyses designed to deal with the DA reading in English such as Abusch 1997 and Gennari 2003, both of which would predict that an eventuality denoted by a present tense verb embedded under a past tense PA verb overlaps with the time of the attitude and with the ST.

These data call for the reassessment of the question about the factors that affect the temporal location of events embedded in PA complements. In Albanian, the relevant information cannot be attributed to the meaning of the present tense alone, as Gennari 2003 proposes for English. The assumption that the present tense encodes an overlap between the event time and the attitude time would make wrong predictions for constructions such as (5). It is also not clear how the de re analyses can be modified to account for the DA reading in (4) and the lack thereof in (5). In what follows, I present an alternative analysis in which the semantics of the present tense and the semantics of the propositional attitude verbs jointly determine the temporal location of the embedded event. My analysis differs from Gennari (2003) and Abusch (1997) in that I assume that PA verbs lexically specify the relationship between the time of the attitude and the time with respect to which the embedded tense is interpreted. ${ }^{2}$ Since this relationship is different for different verbs, the overlap between the time of the attitude and the embedded event time arises when the matrix verb is them 'say', but not when it is vendos 'decide'. In what follows, I spell out the details of this proposal.

\section{Present tense and the meaning of PA verbs in Albanian}

The goal of this section is two-fold: (i) to determine the meaning of the Albanian present tense in two types of intensional environments, subjunctive and indicative complements, and (ii) to establish how the semantics of selecting PA verbs affects the temporal location of the event denoted by the embedded present tense. A comparison of temporal properties of these complements is warranted by the facts that both types of complements considered here are selected by PA verbs, ${ }^{3}$ and, moreover, syntactically, both complements are of the clausal type. ${ }^{4}$ Before I discuss the properties of subjunctive and indicative complements, a few words

2A corollary from this assumption is that the evaluation time of the embedded clause is not necessarily identical to the time of the attitude. I discuss this point in Section 3.

3In principle, subjunctive and indicative complements are selected by various semantic classes of predicates. For example, indicative complements are selected by veridical verbs such as dëgjoj 'hear', by PA verb such as mendoj 'think', and by some modal verbs such as e mundur 'possible'. Similarly, subjunctive complements can be selected by veridical/perceptual verbs such as dëgjoj 'hear', by PA verbs such as premtoj 'promise', and by modals such as duhet 'must'. Only constructions with PA verbs are considered here.

4Support for the clausal status of subjunctive complements comes from the fact that when the subject of the embedded clause is realized overtly, it bears nominative case (see (5)). 
about the meaning of the present tense in matrix clauses are in order.

Two semantic components are of interest here. The first pertains to the question of how the present tense is interpreted, i.e. whether it is ST-sensitive. The distribution of deictic temporal adverbials, i.e. adverbials that establish the time reference with respect to the ST, allows me to answer this question. The fact that in (6), the deictic temporal adverb dje 'yesterday', which shifts the reference time to the past of the ST, is incompatible with the present tense verb suggests that the present tense in Albanian cannot locate events in the past with respect to the ST. That is, the present tense in Albanian is ST-sensitive, or absolute.

$$
\begin{array}{lll}
\text { Unë } & \text { këndo-j tani /nesër /\#dje. } \\
\text { I } & \text { sing-1SG.PRES now/tomorrow/ yesterday } \\
\text { 'I sing now.'/'I sing tomorrow' (it has been decided). }
\end{array}
$$

For events that started and terminated prior to the ST, one of the past tenses, the aorist or the imperfect, must be used (7).

$$
\begin{aligned}
& \text { Këndo-ja dje. } \\
& \text { sing-1SG.IMPRFCT yesterday. } \\
& \text { 'I sang yesterday.' }
\end{aligned}
$$

The second question of interest is whether the present tense is semantically present or non-past. The fact that the present tense in (6) is compatible with the present- and future-oriented adverbials suggests that semantically the present tense is non-past. Note, however, that the future time reference is not available by default but arises only when the sentence with a present tense verb has a modalized "scheduled" interpretation (e.g. Kaufmann 2005). For future nonscheduled events, the future tense must be used (8). ${ }^{5}$

$$
\begin{aligned}
& \text { Do të këndoj nesër. } \\
& \text { FUT SUBJ sing-1SG.PRES tomorrow } \\
& \text { 'I will sing tomorrow.' }
\end{aligned}
$$

In what follows, I examine temporal properties of subjunctive and indicative complements with the embedded present tense.

\subsection{The meaning of the present tense and PA verbs in subjunctive complements}

It is usually assumed in the literature on the Balkan subjunctive (e.g. Landau 2004) that tense in subjunctive complements can be of two types, either 'defective' (i.e. the tense that lacks any semantic content) or 'relative' (i.e. tense

5Here I use the term "future tense" descriptively. In this paper I'm not concerned with the question of whether $d o$ 'will' should be analyzed as a modal, or as a true future tense. 
interpreted with respect to the time of the attitude). However, the Albanian data presented below seem to defy this generalization. Thus in (9), the non-past verb këndoj 'I sing' embedded inside the subjunctive complement ${ }^{6}$ has the properties of an absolute tense - it is not compatible with the past time reference imposed by the adverbial phrase $n \ddot{e} 2005$ 'in 2005'. This suggests that the event denoted by the present tense verb in subjunctive complements cannot be located in the past with respect to the ST. With the past-oriented adverbial, the past imperfect form këndoja 'sang' must be used (10): ${ }^{7}$

Planifikov-a [të këndo-j në Paris tani /në 2012 /\#2005].

plan-1SG.PAST SUBJ sing-1SG.PRES in Paris now/in 2012 / 2005

'I planned to sing in Paris now/in 2012/\# in 2005.'

Planifikov-a [të \#këndo-j /këndo-ja në Paris në 2005].
plan-1SG.PAST SUBJ sing-1SG.PRES/sing-1SG.IMPRFCT in Paris in 2005
'I planned to sing in Paris in 2005.'

Additional support for the analysis of the present tense as absolute comes from the construction in (11). (11a) shows that the embedded present tense verb is not compatible with the past time reference introduced by vjet 'last year'. In order to express the intended proposition, the imperfect past tense must be used (11b).
Edhe mbas 5 vjetësh do të kujto-j
si ...
even after 5 years FUT SUBJ remember-1SG.PRES how
a. [të këndo-jë tani /\#vjet / \#nesër].
SUBJ sing-3SG.PRES now/last.year / tomorrow.

6Subjunctive complements in Albanian are introduced by the modal marker të. Unlike other Balkan languages such as Bulgarian and Greek, subjunctive verbs have designated subjunctive morphology, even though it is somehow 'defective' since it appears in the $2^{\text {nd }}$ and $3^{\text {rd }}$ person singular forms only. All other forms are identical to that in the indicative paradigm:

\begin{tabular}{|c|c|c|c|c|c|c|}
\hline Indi & $\operatorname{tiv}$ & esent: & & \multicolumn{3}{|c|}{ Subjunctive Present } \\
\hline $1 \mathrm{SG}$ & $-\mathrm{j}$ & $1 \mathrm{PL}$ & -jmë & $1 \mathrm{SG}$ & $-\mathrm{j}$ & $1 \mathrm{PL}$ \\
\hline $2 \mathrm{SG}$ & $-n$ & $2 \mathrm{PL}$ & $-n i$ & $2 \mathrm{SG}$ & $-(\ddot{e}) s h$ & $2 \mathrm{PL}$ \\
\hline $3 \mathrm{SG}$ & $-n$ & $3 \mathrm{PL}$ & -jnë & $3 \mathrm{SG}$ & $-\mathbf{j e ̈}$ & $3 \mathrm{PL}$ \\
\hline
\end{tabular}

It seems, however, that the subjunctive morphology does not have any special temporal import, since, as I show below, the meaning of the present tense is the same in indicative and in subjunctive complements. This suggests that the subjunctive morphology might be carrying a special modal meaning, such as the expression of the epistemic commitment on the speaker's part (Smirnova 2009), but does not seem to hane any temporal contribution.

7 Note that the requirement to use the past tense morphology in (10) cannot be attributed to counterfactuality. The construction in (10) can be continued by either (i) or (ii), which suggests that it can but does not have to have a counterfactual reading. What triggers the past tense in (10) is the past time reference and not the counterfactual construal.
(i) dhe këndov-a 'and I sang'
(ii) por nuk këndov-a 


\section{b. [të këndo-nte vjet] \\ SUBJ sing-3SG.IMPRFCT last.year}

'Even in 5 years from now I will (still) remember

(a) ... how she is singing now.'/(b) '...how she sang last year.'

Turning now to the question about the location of the embedded event relative to the time of the attitude, notice that the present tense verb in (9) is compatible with the future time reference. However, unlike in matrix clauses like in (6), the future time reference in (9) is not licensed by a "modalized" scheduling context. The example in (9) can be uttered in a context in which nothing guarantees the realization of the singing event. I argue that the factor responsible for the future time reference in (9) is the semantics of the future-oriented verb planifikoj 'plan', which shifts forward the time with respect to which the embedded clause is interpreted. When the embedded present tense is evaluated with respect to this forward-shifted time, the embedded event is understood to be located in the future with respect to the time of the attitude. Verbs such as 'remember' have the opposite effect. They shift the evaluation time of the embedded clause to the past. The present tense verb këndojë 'sing' in (12) cannot appear in the subjunctive complement selected by the past tense verb kujtoj 'remember' because the present tense verb would locate the event of singing at the ST, which is in the future with respect to the time of remembering.
$\mathrm{Mu}$ kujtua
[ai të këndo-nte
/\#këndo-jë].
me remember-1SG.PAST he SUBJ sing-3SG.IMPRFCT/ sing-3SG.PRES
'I remember him singing.'

To summarize, this section showed that present tense in embedded subjunctive complements in Albanian is absolute; it cannot locate events in the past to the ST. We also have seen that the semantics of matrix verbs imposes constraints on how the embedded event is located with respect to the time of the attitude. ${ }^{8}$

\subsection{The meaning of the present tense and $P A$ verbs in indicative complements}

In this section, I discuss the temporal properties of indicative complements with the embedded present tense selected by verbs such as them 'say'. As far as the meaning of the present tense is concerned, the data presented in (4), as well as example (13) below show that embedded present tense verbs cannot denote events that terminated prior to the ST. This confirms an earlier observation that the present tense is ST-sensitive. The example in (13) is infelicitous because the present tense requires that the event of Enver Hoxha's living in Albania holds at the ST. Since the Albanian dictator is no longer alive, this condition cannot be

8See Smirnova (2009) for a detailed discussion on temporal properties of forward- and backshifting verbs in subjunctive complements in Bulgarian. 
satisfied.

(13) Context: In 1970 Enver Hoxha, the leader of the Albanian communist party, lived in Tirana. Your mother recalls taking a history class back then: \# Pedagogu tha [se Enver Hoxha jeto-n në Tiranë]. professor say.3SG.PAST that Enver Hoxha live.3SG.PRES in Tirana Intended: 'The professor said that Enver Hoxha lived in Tirana.'

Consider now the question about the temporal location of the embedded event with respect to the time of the attitude. The examples in (14) and (15) show that when present tense verbs are selected by them 'say' (the same generalization holds for mendoj 'think'), it is required that the time of the embedded event overlap with the time of the attitude. This requirement is reinforced by the contexts in (14) and (15) (see also (4)). In (14), Maria is Beni's wife at the time of his conversation with his parents, and in (15), the singing overlaps with the usher's saying time.

(14) Context: Beni's parents are opposed to his marriage to Maria. While they are away on a month-long trip, Beni has arranged a secret wedding that will take place next weekend. When he sees his parents next month, he will tell them the news.

Beni do tu thotë atyre [se Maria është gruaja e tij]. Beni FUT SUBJ say.3SG.PAST parents that Maria be.3SG.PRES wife his 'Beni will tell his parents that Maria is his wife.'

(15) Context: You are late for the opera, and are asked to wait for the intermission. You hear beautiful singing, but you don't know whose voice it is. Your sister, who just spoke with the usher reports the following: Shoqëruesi tha [se këndo-n Inva Mula]. usher say.3SG.PAST that sing-3SG.PRESInva Mula 'The usher said that Inva Mula is singing.'

The examples above show that the embedded event denoted by the present tense has to overlap with the time of the attitude regardless of whether the matrix verb is in the future (14) or in the past tense (15). However, there is an interesting difference between (14) and (15). With the future tense matrix verb the overlap with the ST is possible but not obligatory. In the context preceding (14), the wedding is scheduled for a future time, so the overlap with the ST does not arise. But in principle, the example in (14) is also compatible with contexts in which the wedding has already taken place, and thus Maria is Beni's wife at the time when (14) is uttered. However, with the past tense matrix verbs, as in (4), (13), and (15), the overlap with the ST is mandatory. This gives rise to the DA reading. The fact that this reading arises only with a past tense matrix verb is a consequence of two 
factors. First, the event denoted by the present tense verb has to overlap with the time of the attitude in complements selected by verbs such as them 'say'. In (15), the time of the attitude is before the ST. Second, according to the meaning of the present tense, the embedded event cannot terminate prior to the ST. To satisfy these two conditions, the embedded event has to overlap with the ST.

One question that remains unanswered at this point is what factors are responsible for the temporal overlap between the time of the attitude and the time of the embedded event in examples with the embedded present tense such as (14) and (15). If we encode the overlap in the meaning of the present tense as Gennari (2003) proposes for English, we get the wrong results for cases in which the present tense verb is selected by predicates such as planifikoj 'plan', which require the two events to be sequentially ordered. To avoid this consequence, we could assume that present tense has different meanings in indicative and in subjunctive complements, but this assumption would contradict the observation that present tense is absolute in both complement types, and so a uniform analysis is to be preferred. At the same time, we cannot assume that matrix verbs like them 'say' encode the overlap between the time of the attitude and the embedded event time as part of their lexical semantics, since such verbs do not impose constraints on the temporal location of the embedded event. Depending on what the embedded tense is, the embedded event can be located in the past or in the future with respect to the time of the attitude. In order to account for the data, and at the same time avoid the negative consequences discussed above, I assume that verbs such as them 'say' specify that the the attitude time overlaps with the time with respect to which the embedded tense is interpreted.

\section{Compositional semantic analysis}

I adopt a formal framework where tenses are temporal modifiers of type $<<i, t>$, $<i, t>>$. They specify the relationship between the Event Time (ET) and the evaluation time $\left(t_{\text {eval }}\right)$. Since the present tense in Albanian is absolute, the evaluation time in this case is lexically specified as the Speech Time. In (16), I use the designated variable $s t$ for this purpose.

$$
\mathrm{PRES} \Rightarrow \lambda P_{<i, \triangleright} \lambda t[P(t) \& \neg(t<s t)]
$$

I assume that past and future tenses in matrix clauses are interpreted as in (17a) and (17b), respectively: ${ }^{9}$

9 Even though in this paper I don't discuss temporal properties of past and future tense complement clauses, it should be noted that embedded past and future tenses are not ST-sensitive or indexical. I assume that in embedded clauses they are interpreted as in (ia) and (ib), respectively:
(i) a. $\mathrm{PAST}_{\text {embed }} \Rightarrow \lambda P_{<i, \triangleright} \lambda t^{\prime} \exists t\left[P(t) \& t<t^{\prime}\right]$
b. FUTURE embed $\Rightarrow \lambda P_{<i, \triangleright} \lambda t^{\prime} \exists t\left[P(t) \& t^{\prime}<t^{\prime}\right]$ 

a. PAST $\Rightarrow \lambda P_{<i, \triangleright} \lambda t[P(t) \& t<s t]$
b. FUTURE $\Rightarrow \lambda P_{<i, \triangleright}>\lambda t[P(t) \& t>s t]$.

The derivation of a simple present tense sentence, as in (6), proceeds as follows. Tenses are applied to sentence radicals (untensed sentences). The sentence radical of Unë këndoj 'I sing' in (18) denotes a set of times $T$, such that for all times $t \in \mathrm{T}$, the speaker $(s p)$ sings at $t$.

$$
\text { I sing } \Rightarrow \lambda t\left[\operatorname{sing}^{\prime}(t)(s p)\right]
$$

The present tense in (16) takes (18) as an argument, and the application of existential closure gives the result in (19):

$$
\exists t^{\prime}\left[\operatorname{sing}^{\prime}\left(t^{\prime}\right)(s p) \& \neg\left(t^{\prime}<s t\right)\right]
$$

The formula in (19) is interpreted with respect to a model $M$, an assignment function $g$, and the ST $(s t)$.

(20) $\quad\left[\exists t^{\prime}\left[\operatorname{sing}^{\prime}\left(t^{\prime}\right)(s p) \& \neg\left(t^{\prime}<s t\right)\right] \rrbracket^{\mathrm{M}, \mathrm{g}, \text { st }}=1\right.$ iff there exists an interval $t^{\prime}$ of speaker's $s p$ singing, and $t^{\prime}$ does not precede the ST (st).

\subsection{Subjunctive complements}

Unlike sentence radicals of simple verbs such as këndoj 'sing' which denote functions from time intervals to truth values, sentence radicals of the PA verbs such as planifikoj 'plan' or kujtoj 'remember' are of type $\langle<w,\langle i, t>>,\langle i, t\rangle>$.

$$
\begin{aligned}
& \text { a. } \quad \text { plan } \Rightarrow \lambda Q \lambda t\left[\text { plan }^{\prime}(t)(s p)\left(\wedge \lambda t^{\prime} \exists t^{\prime \prime}\left[Q\left(t^{\prime \prime}\right) \& t^{\prime}<t^{\prime \prime}\right]\right)\right] \\
& \text { b. } \quad \text { remember } \Rightarrow \lambda Q \lambda t\left[\text { remember }(t)(s p)\left(\wedge \lambda t^{\prime} \exists t^{\prime \prime}\left[Q\left(t^{\prime}\right) \& t^{\prime \prime}<t^{\prime}\right]\right)\right] \\
& \text { where } t=\mathrm{ET}_{\text {main }}, t^{\prime}=\text { attitude holder's now, } t^{\prime \prime}=t_{\text {eval }}, s p=\text { speaker }^{10}
\end{aligned}
$$

The temporal relation $t^{\prime}<t^{\prime \prime}$ in the meaning of planifikoj 'plan' in (21a) specifies that the evaluation time $t^{\prime \prime}$ with respect to which the embedded tense is interpreted is in the future of the time of the attitude $t^{\prime}$. The relationship between these two times is reversed in the meaning of 'remember'. In the process of semantic derivation, the time of evaluation $t^{\prime \prime}$ in the definitions in (21) is identified with the ET (due to the meaning of the present tense). When the embedded tense is past or future, the time of evaluation $t^{\prime \prime}$ in the definitions in (21) is identified with the time of evaluation supplied by the meaning of the past or the future tense. Now consider (22):

10 In the sentence radicals in (21) the subject argument is the speaker $(s p)$, but it can in principle be any other individual. 
Planifikov-a [të këndo-j nesër /\#dje].

plan-1SG.PAST SUBJ sing-1SG.PRES tomorrow/ yesterday.

'I planned to sing tomorrow/\#yesterday.'

The semantic derivation of (22) proceeds as in (23).

Derivation of (22):

a. $\quad$ PRES $((18))=\lambda t^{\prime \prime \prime}\left[\operatorname{sing}\left(t^{\prime \prime \prime}\right)(s p) \& \neg\left(t^{\prime \prime \prime}<s t\right)\right]$

b. $\quad$ plan $((23 \mathrm{a}))=\lambda Q \lambda t\left[p l a n^{\prime}(t)(s p)\left(\wedge \lambda t^{\prime} \exists t^{\prime \prime}\left[Q\left(t^{\prime \prime}\right) \& t^{\prime}<t^{\prime}\right]\right)\right]$

$\left(\lambda t^{\prime \prime \prime}\left[\operatorname{sing}\left(t^{\prime \prime \prime}\right)(s p) \& \neg\left(t^{\prime \prime \prime}<s t\right)\right]\right)$

$=\lambda t\left[\operatorname{plan}^{\prime}(t)(s p)\left(\wedge \lambda t^{\prime} \exists t^{\prime \prime}\left[\operatorname{sing}^{\prime}\left(t^{\prime \prime}\right)(s p) \& \neg\left(t^{\prime \prime}<s t\right) \& t^{\prime}<t^{\prime \prime}\right]\right)\right]$

c. PAST $((23 \mathrm{~b}))=\lambda P \lambda t[P(t) \& t<s t]\left(\lambda t\left[\right.\right.$ plan $(t)(s p)\left({ }^{\wedge} \lambda t^{\prime} \exists t^{\prime \prime}\left[\operatorname{sing}^{\prime}\right.\right.$

$\left.\left.\left.\left.\left(t^{\prime \prime}\right)(s p) \& \neg\left(t^{\prime \prime}<s t\right) \& t^{\prime}<t^{\prime \prime}\right]\right)\right]\right)$

$=\lambda t\left[\operatorname{plan}^{\prime}(t)(s p)\left(\wedge^{\wedge} t^{\prime} \exists t^{\prime \prime}\left[\operatorname{sing}^{\prime}\left(t^{\prime \prime}\right)(s p) \& \neg\left(t^{\prime \prime}<s t\right) \& t^{\prime}<t^{\prime}\right]\right) \& t<s t\right]$

The matrix verb planifikoj 'plan' takes as an argument the temporal abstract in (23a), derived from the application of the present tense (16) to the meaning of the sentence radical $I$ sing in (18). This application produces a temporal abstract of type $<i, t>$ in (23b). The application of the matrix past tense yields another temporal abstract in (23c). Existential closure applies yielding (24) as the final interpretation:

$$
\exists t\left[\operatorname{plan}^{\prime}(t)(s p)\left(\wedge \lambda t^{\prime} \exists t^{\prime \prime}\left[\operatorname{sing}^{\prime}\left(t^{\prime \prime}\right)(s p) \& \neg\left(t^{\prime \prime}<s t\right) \& t^{\prime}<t^{\prime}\right]\right) \& t<s t\right]
$$

Assuming the traditional definition of PA verbs in which the complements are evaluated with respect to the set of worlds (doxastic alternatives) available to the speaker at the time of the attitude, the translation in (24) has the following truth conditions. (24) is true iff there exists a time $t$ of the speaker's planning, which is located in the past of the ST $(t<s t)$, such that in all doxastic alternatives of the speaker accessible from $t$, there exists an event of singing at $t^{\prime \prime}$, and the time interval $t^{\prime \prime}$ is such that it does not precede the $s t\left(\neg\left(t^{\prime \prime}<s t\right)\right),{ }^{11}$ and is located in the future with respect to the attitude holder's now $t^{\prime}\left(t^{\prime}<t^{\prime \prime}\right)$. Note that the truth conditions of (24) do not directly specify the relationship between the time of planning in the real world $t$ and the time of the attitude in the belief world $t^{\prime}$. The identity relation $\left(t=t^{\prime}\right)$ is entailed under the assumption that the speaker correctly locates herself in time.

The analysis presented above correctly predicts that the DA reading cannot arise in complements of verbs such as planifikoj 'plan'. Since these verbs specify that the evaluation time of the embedded event is in the future with respect to the attitude time, and since the time of the embedded event is identified with the evaluation time (due to the meaning of the present tense), the matrix and the

11I return to the question about the status of the indexical variable st in intensional complements in Section 3.2. 
embedded events are sequentially ordered.

This analysis also correctly predicts that (22) would not be compatible with a past-oriented adverbial. Such an adverbial would restrict the time of the singing eventuality to the past, but this would not be compatible with the meaning of the present tense:

$$
\begin{aligned}
& \exists t\left[\text { plan } ^ { \prime } ( t ) ( s p ) \left(\wedge \lambda t ^ { \prime } \exists t ^ { \prime \prime } \left[\operatorname{sing}^{\prime}\left(t^{\prime \prime}\right)(s p) \& \underline{\neg\left(t^{\prime \prime}<s t\right)} \& t^{\prime}<t^{\prime \prime} \&\right.\right.\right. \\
& \left.\left.\left.\underline{t^{\prime \prime} \subset \text { yesterday }}\right]\right) \& t<s t\right]
\end{aligned}
$$

The semantic derivation of the sentence with the matrix verb kujtoj 'remember' proceeds along the same lines as in (23), and yield the translation in (27):

$$
\text { Do të kujto-j si [të këndo-jë tani /\#vjet]. }
$$

FUT SUBJ remember-1SG.PRES how SUBJ sing-3SG.PRES now / last.year.

'I will remember how she is singing now/\#last year.'

$$
\exists t\left[\operatorname{remember}^{\prime}(t)(s p)\left(\wedge \lambda t^{\prime} \exists t^{\prime \prime}\left[\operatorname{sing}^{\prime}\left(t^{\prime \prime}\right)(i) \& \neg\left(t^{\prime \prime}<s t\right) \& t^{\prime \prime}<t^{\prime}\right]\right) \& t>s t\right]
$$

(27) is true iff there exists a time $t$ of the speaker's remembering, located in the future with respect to the $s t(t>s t)$, such that for all doxastic alternatives accessible from $t$, there exists a time $t^{\prime \prime}$ of the individual $i$ singing such that $t^{\prime \prime}$ does not precede the $s t\left(\neg\left(t^{\prime \prime}<s t\right)\right)$, and the attitude holder's now $t^{\prime}$ is in the future with respect to singing $\left(t^{\prime \prime}<t^{\prime}\right)$.

Consider now what happens when a past tense matrix verb 'remember' selects a present tense complement. The analysis predicts that such a construction, whose translation is given in (28), would be infelicitous because the meaning of the present tense and the meaning of the verb would impose conflicting conditions on the temporal location of the singing event.

$$
\exists t\left[\operatorname{remember}^{\prime}(t)(s p)\left(\wedge \lambda t^{\prime} \exists t^{\prime \prime}\left[\operatorname{sing}^{\prime}\left(t^{\prime \prime}\right)(i) \& \neg\left(t^{\prime \prime}<s t\right) \& t^{\prime \prime}<t^{\prime}\right]\right) \& t<s t\right]
$$

The meaning of the matrix past tense specifies that the time of remembering is in the past with respect to the ST $(t<s t)$. Under the assumption that the speaker correctly locates herself in time, the time of the remembering in the real world would be identified with the time of the attitude in the speaker's world $\left(t=t^{\prime}\right)$. Therefore, in the belief world the time of the attitude is also in the past with respect to the ST $\left(t^{\prime}<s t\right)$. The lexical semantics of kujtoj 'remember' specifies that the time of singing is in the past with respect to the time of remembering $\left(t^{\prime \prime}<t^{\prime}\right)$. It follows then that the time $t^{\prime \prime}$ of singing should also be located in the past with respect to the ST $\left(t^{\prime \prime}<s t\right)$. This condition contradicts the meaning contributed by the present tense $\left(\neg\left(t^{\prime \prime}<s t\right)\right)$.

The analysis presented in this section accounts for the meaning of tenses in complements selected by planifikoj 'plan' and kujtoj 'remember', and explains 
why the DA interpretation does not arise in these constructions.

\subsection{Indicative complements}

As we observed in Section 2.2, the definition of verbs such as them 'say' should reflect the fact that any temporal order between the time of the attitude and the embedded event is possible, but also account for the fact that the overlap with the time of the attitude is obligatory when the embedded tense is present. The translation in (29) achieves this goal:

$$
\begin{aligned}
\text { 'say' } \Rightarrow & \lambda Q \lambda t\left[\operatorname{say}^{\prime}(t)(s p)\left(\wedge \lambda t^{\prime} \exists t^{\prime \prime}\left[Q\left(t^{\prime \prime}\right) \& t^{\prime} o t^{\prime \prime}\right]\right)\right] \\
& \text { where 'o' means 'overlaps with' }
\end{aligned}
$$

When the embedded tense is present, the temporal variable $t^{\prime \prime}$ is identified with the event time of the embedded verb. To see how this works, consider the translation of (30) given in (31):

$$
\text { Pjetri tha [se Maria është shtatzënë]. }
$$

Peter say.3SG.PAST that Maria be.3SG.PRES pregnant.

'Peter said that Maria is pregnant.'

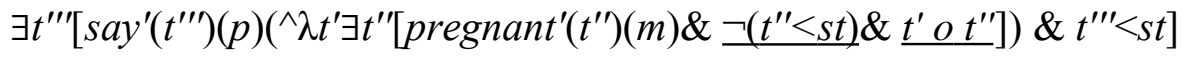

The condition $\neg\left(t^{\prime \prime}<s t\right)$, which comes from the meaning of the tense, and the condition $t^{\prime} o t^{\prime \prime}$, guarantee that the embedded event that holds at the interval $t^{\prime \prime}$ overlaps with the time of the attitude $t^{\prime}$, and with the ST, thus giving rise to the DA reading. ${ }^{12}$ Note also that according to the translation in (31), the state of Maria's pregnancy exists in Peter's belief worlds but not necessarily in the actual world. This is a welcome outcome. It is compatible with situations in which Maria is not pregnant in the actual world but simply appears to be bigger than usual, and Peter (mistakenly) attributes this to pregnancy (cf. Abusch 1997 on English).

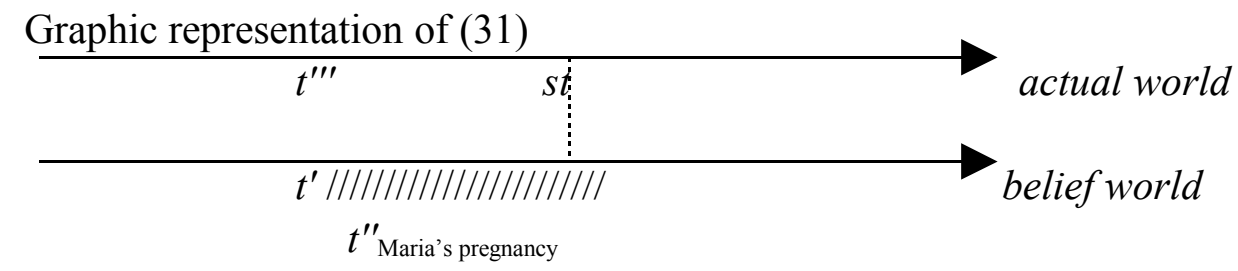

The final point that still needs to be discussed is the prediction that the

12 When the embedded tense is past, the meaning of them 'say' gives rise to the overlap between the time of the attitude and the evaluation time of the embedded verb. The embedded past tense (see footnote 9) locates the embedded event in the past with respect to its evaluation time, and also with respect to the attitude time. 
state of Maria's pregnancy in (30) in Peter's belief worlds is supposed to hold at the ST (condition $\left.\neg\left(t^{\prime \prime}<s t\right)\right)$. It implies that Peter's original report contained information that Maria would be pregnant at the ST. Intuitively, however, when Peter said "Maria is pregnant", he was not aware when the sentence in (30) would be uttered, so he didn't have access to the ST, a future time from his perspective. In order to explain the appearance of the indexical variable st in an intensional environment, I adopt an analysis in terms of the attribution of implicit attitudes proposed by Gennari (1999), (2003) for English. According to Gennari, when the speaker of (30) uses the present tense, she does not represent the belief of the subject de dicto (literally). In (30) it would mean that Peter believed that Mary would be pregnant at the ST. Instead, the use of the indexical present tense, and the implication that Maria is pregnant at the ST, follows from the inferences available in the common ground. The speaker can utter (30) granted that (i) Peter knew that Mary was pregnant at some past time $t^{\prime}$, (ii) Peter knows that pregnancies usually last for 9 months, (iii) Peter assumes that Mary has a normal pregnancy, and therefore she will continue to be pregnant for some time in the future, and (iv) the future time at which Mary is pregnant also includes the st. Even though Peter did not have a literal belief about the ST, his belief may be inferred from his world knowledge (represented by the propositions in the common ground) and the content of the literal belief. Thus the indexical variable st in an intensional context is a manifestation of the speaker's attribution of an implicit attitude to the original attitude holder, rather the attitude holder's representation of the ST.

\subsection{Summary of the proposed analysis}

According to the analysis presented in this section, the temporal location of the embedded event is constrained by the meaning of the embedded tense, and by the semantics of PA verbs. I argued that the present tense in Albanian is absolute and has the same meaning in matrix clauses and in subjunctive and indicative complements selected by PA verbs. Regarding the semantics of PA verbs, I propose that they lexically specify the relationship between the time of the attitude and the time with respect to which the embedded tense is interpreted. In this analysis, the attitude verbs are of the same semantic type, and semantic derivations obey compositionality. In the next section, I compare the proposed analysis to the analyses proposed for English, and discuss the aspects that make their application to Albanian untenable.

\section{Previous analyses}

\subsection{De re analyses of the present tense in English}

In this section, I discuss in more detail Abusch's (1997) de re analysis designed to 
explain the DA reading in English, and consider whether it is possible to modify this analysis so that it can account for the Albanian data.

I first discuss problems that arise from the assumption that the present tense is interpreted de re. Recall that de re analyses require (i) the existence of a state in the actual world that overlaps both with the belief time and with the ST, and (ii) the existence of a suitable acquaintance relation that relates the attitude holder to the state in the actual world (see 3). If one of these conditions is not met, the sentence with the embedded present tense is predicted to be infelicitous. As Gennari (2003) points out, these two assumptions are problematic for English. Similar problems arise in Albanian. Consider a scenario in which Beni, a psychologically unstable individual, is confined to a psychological ward. A psychiatrist who works with Beni can report his condition as in (33):

$$
\begin{aligned}
& \text { Beni halucino-nte [se Maria është aljon]. } \\
& \text { Beni hallucinate-3SG.IMPRFCT that Maria be.3SG.PRES alien } \\
& \text { 'Beni hallucinated that Maria was an alien.' }
\end{aligned}
$$

If Beni hallucinated last night in the clinic, he could not have had any contacts with Maria in the actual world, and, consequently, could not form a suitable acquaintance relation. Unlike what is predicted by the de re analyses, the present tense verb in (33) seems to refer not to a state in the actual world, but to a state in Beni's belief worlds. This example suggests that the embedded present tense does not always give rise to the de re interpretation. But what happens if we drop the problematic assumption about the de re interpretation? Would it be possible to account for the Albanian data in Abusch's framework in that case? I show below that there are several aspects of Abusch's analysis that make its application to Albanian untenable.

First, one of the central components of Abusch's analysis is the Upper Limit Constraint according to which "the now of an epistemic alternative is an upper limit for the denotation of tenses" (Abusch 1997: 24). This constraint predicts that in sentences such as Peter believed that Maria was sick, the embedded past cannot have a forward-shifted interpretation $\left(\mathrm{t}_{\text {believe }}<\mathrm{t}\right.$ sick $)$. The proponents of Abusch's theory might suggest that such a constraint is needed to explain the lack of the forward-shifted reading in Albanian. However, if we assume that the Upper Limit Constraint applies in Albanian, we would incorrectly rule out the forward-shifted reading in complements of verbs such as planifikoj 'plan' and vendos 'decide'. ${ }^{13}$

Second, Abusch's analysis predicts that constructions such as Peter believed that Maria was sick, are ambiguous between an overlapping ( $\left.\mathrm{t}_{\text {believe }} \mathrm{O} \mathrm{t}_{\text {sick }}\right)$ and a back-shifted $\left(\mathrm{t}_{\text {believe }}<\mathrm{t}_{\text {sick }}\right)$ interpretation. The same pattern is attested in Albanian:

13I thank Yael Sharvit for a stimulating discussion of this aspect. 
Pjetri tha [se Maria ishte e sëmurë].

Peter say.3SG.PAST that Maria be.3SG.PAST LINK sick.

'Peter said that Maria was sick.'

a. he was going to the pharmacy to get her some medicine. [ $\mathrm{t}_{\text {say }} \mathbf{o} \mathrm{t}_{\text {sick }}$ ]

b. but she has completely recovered by now. $\left[\mathrm{t}_{\text {sick }}<\mathrm{t}_{\text {say }}\right]$

However, in Albanian such an ambiguity is only attested in constructions with matrix verbs such as them 'say' but not with kujtoj 'remember' or planifikoj 'plan', which unambiguously produce a back-shifted or a forward-shifted interpretation. Since in Abusch's framework the overlapping reading is a consequence of the meaning of the embedded tense, it is not possible to rule it out without radically altering the whole system.

Finally, in Abusch's analysis, tenses are inherently relative, and what serves as the evaluation time depends on the position of tense. The embedded present tense in sentences such as Peter said that Maria is pregnant obligatorily moves to an extensional position outside the intensional complement, where it is interpreted with respect to the ST. However, if we make this assumption, the evaluation time of the embedded tense in constructions selected by kujtoj 'remember' or planifikoj 'plan' would no longer be constrained by the matrix verb, but thenthe effect of the matrix verb on the temporal location of the embedded event, discussed in Section 2, would be unexplained.

This discussion suggests that the analysis proposed by Abusch cannot account for the Albanian data.

\subsection{Katz's 2002 analysis of 'expect' and 'believe' in English}

In this section I discuss Katz's 2002 analysis of constructions selected by 'futureoriented' verbs such as expect and 'present oriented' verbs such as believe in English. Katz's analysis is similar to mine in that he assumes that verb expect lexically constrains the temporal location of the embedded event. In (35), the condition $t^{\prime \prime}>t^{\prime}$ supplied by the meaning of expect guarantees that that the time of the embedded event $t^{\prime \prime}$ is in the future with respect to the attitude holder's now $t^{\prime} .^{14}$

$\llbracket$ expect $\rrbracket(w, t, x, P)=1$ iff $\left.\forall\left\langle w^{\prime}, t^{\prime}, x^{\prime}\right\rangle \in \operatorname{Dox}(w, t, x) \exists t^{\prime \prime}\right\rangle_{w^{\prime}} t^{\prime} P\left(w, t^{\prime \prime}, t^{\prime}, x^{\prime}\right)=1$ Semantic type of expect: $<<<e<i<i<s t>>>><e<i<s t>>>>$

For verbs such as believe, Katz adopts a more traditional definition, according to which the verb does not lexically specify the relationship between the attitude time and the embedded event time. This is why there is no variable corresponding to the embedded event time in (36). As a consequence of these assumptions, the

14While Katz assumes that verbs such as expect encode a relationship between the attitude time and the embedded event time, in my analysis the relationship in question is between the attitude time and the evaluation time, i.e. the time with respect to which the embedded tense is interpreted. 
two verbs look for clausal arguments of different semantic types.

$\llbracket$ believe $\rrbracket(w, t, x, P)=1$ iff $\forall<w^{\prime}, t^{\prime}, x^{\prime}>\in \operatorname{Dox}(w, t, x) P\left(w^{\prime}, t^{\prime}, x^{\prime}\right)=1$

Semantic type of believe: $<<<e<i<$ st $>>><e<i<$ st $>>>>$

Consider what happens when believe and expect select the same complement as in (37a) and (38a). (37b) and (38b) show that these constructions have different LFs.

a. John believes that it will be raining.

b. John ${ }_{0}$ PRES $_{1}$ believes that $\lambda 1$ [it ${ }_{1}$ FUTURE $_{2}$ be raining]

a. John expects that it will be raining.

b. John ${ }_{0} \mathrm{PRES}_{1}$ believes that $\lambda 1 \lambda 2$ [it ${ }_{1} \mathrm{FUTURE}_{2}$ be raining]

With respect to (37b), Katz assumes that lambda abstraction applies and binds a temporal variable corresponding to the evaluation time of the embedded tense (index 1 on the left side of FUTURE). In (38b), lambda abstraction applies twice, once binding a temporal variable corresponding to the event time, and the second time binding a temporal variable corresponding to the evaluation time of the verb rain (index 2 on the right side of FUTURE). There is no independent motivation for the double application of lambda abstraction in (38b). It simply guarantees that the complement in (38) is of the right semantic type, and that it can be taken as an argument by expect. Is not clear what prevents lambda abstraction from applying twice in (37b). This problem does not arise if believe similar to expect, encodes a temporal relation between the attitude time and the evaluation time of the embedded tense as part of its lexical semantics, as I proposed in Section 3.

\section{Conclusions}

The data and the analysis presented in this paper have several empirical and theoretical consequences. From a typological perspective, the Albanian data show that unlike what is often assumed in the literature, the DA phenomenon is not unique to English. On a theoretical side, the Albanian data suggest that the DA phenomenon cannot be explained in terms of the meaning of the present tense alone, as Gennari (2003) proposes for English. The fact that in Albanian present tense verbs embedded in PA complements do not always yield the the DA interpretation suggests that the meaning of the present tense, and in particular, its indexicality, is a necessary but not a sufficient condition for the DA reading. This discussion pertains to a more general question about the factors that affect the interpretation of tenses embedded under PA verbs. In this paper I proposed that the semantic of the embedding PA verbs, as well as the meaning of the embedded 
tense jointly affect the temporal location of the embedded event.

\section{References}

Abusch, Dorit: 1997, 'Sequence of Tense and Temporal de re', Linguistics and Philosophy 20, 1-50.

Abusch, Dorit: 1991, 'The Present under Past as de re Interpretation', in Proceedings of WCCFL 10, Stanford, CSLI Publications.

Arregui, Anna and Kiyomi Kusumoto: 1998, 'Tense in temporal adjunct clauses', in D. Strolovitch and A. Lawson (eds.) Proceedings of SALT VIII, CLC Publications, Cornell University, Ithaca.

Gennari, Silvia: 1999, 'Embedded present tense and attitude reports', in T. Matthews and D. Strolovitch (eds.) Proceedings of SALT IX, CLC Publications, Cornell University, Ithaca.

Gennari, Silvia: 2003, 'Tense meaning and temporal interpretation', Journal of Semantics 20, 35-71.

Heim, Irene: 1994, Comments on Abusch's Theory of Tense. Ms.

Katz, Graham: 2002, 'Tense Selection and the Temporal Interpretation of Complement Clauses', in In G. Katz, S. Reinhard, and P. Reuter (eds.) Proceedings of $\mathrm{SuB}$ 6, University of Osnabrück.

Kaufmann, Stefan: 2005, 'Conditional Truth and Future Reference', Journal of Semantics 22, 231-280.

Kondrashova, Natalia: 1998, 'Embedded Tenses in English and Russian', ms., Cornell University, Ithaca.

Kubota, Yusuke, Jungmee Lee, Anastasia Smirnova and Judith Tonhauser: 2009, 'The Cross-Linguistic Interpretation of Embedded Tenses,' in A. Riester and T. Solstad (eds.) Proceedings of SuB13, Universität Stuttgart.

Kusumoto, Kiyomi: 1999, Tense in Embedded Context. Doctoral Dissertation, University of Massachusetts at Amherst.

Landau, Idan: 2004, 'The scale of finiteness and the calculus of Control', Natural Language and Linguistic Theory 22:811-877.

Ogihara, Toshiyuki: 1996, Tense, Attitude, and Scope, Kluwer, Dordrecht.

Sharvit, Yael: 2003. 'Embedded Tense and Universal Grammar', Linguistic Inquiry 34, 669-681.

Smirnova, Anastasia: 2009, 'A Case against 'Defective' Tense in the Bulgarian Subjunctive,' in J. Reich, M. Babyonyshev, and D. Kavitskaya (eds.) Proceedings of FASL 17: the Yale Meeting, Michigan Slavic Publications.

Smirnova, Anastasia: 2009, Cross-linguistic perspectives on Tense and Modality: a case study of the subjunctive in languages of the Balkans. Doctoral Dissertation (in preparation). The Ohio State University.

von Stechow, Arnim: 1995, Tense in intensional contexts: Two semantic accounts of Abusch's Theory of Tense. Ms, University of Tübingen. 